\title{
Beclomethasone Dipropionate/Formoterol Fumarate Inhalation Solution
}

National Cancer Institute

\section{Source}

National Cancer Institute. Beclomethasone Dipropionate/Formoterol Fumarate

Inhalation Solution. NCl Thesaurus. Code C162757.

An inhalation solution composed of a fixed combination of the dipropionate salt form of the synthetic glucocorticoid beclomethasone and the fumarate salt form of the longacting and selective sympathomimetic beta-receptor agonist formoterol, with antiinflammatory and bronchial smooth muscle-relaxing activities. Upon pressurized inhalation of the beclomethasone/formoterol solution, beclomethasone binds to intracellular glucocorticoid receptors (GRs), exhibiting inhibitory activities ag ainst multiple cell types and mediators associated with allergic inflammation. Formoterol selectively binds to beta-2 adrenergic receptors in bronchial smooth muscle, activating intracellular adenylyl cyclase, an enzyme that catalyzes the conversion of adenosine triphosphate (ATP) to cyclic-3', 5'-adenosine monophosphate (cAMP). Increased intracellular cAMP results in the relaxation of bronchial smooth muscle and inhibition of the cellular release of mediators of immediate hypersensitivity, especially from mast cells. This may improve lung function. 